\title{
A field study on Ground Energy Balance calculation for typical communities in South China
}

\author{
Riyi Li, Yufeng Zhang*, Chongyun Huang, Chundian He
}

State Key Laboratory of Subtropical Building Science, Department of Architecture, South China University of Technology, Guangzhou, China

\begin{abstract}
Urban heat island (UHI) greatly influences human health, comfort and building energy. The ground temperature plays an important role in understanding UHI, and the method based on the ground energy balance (GEB) is fundamental in the predictions of urban ground temperature and UHI. South China is fast developed and highly urbanized, with special humid subtropical climate and particular urban design characteristics. Although amounts of methods or formulas have been previously proposed for urban GEB calculation, few of them has been testified in field in South China. In this study, two typical urban communities in South China in the aligned and enclosed layout were measured during the summer sunny days in Aug. 2017, with the focus on incident solar radiation, sensible heat, and latent heat of the ground. The measured data were compared with the calculated ones by various methods. The results show that the two calculation methods, i.e., with and without reflections, showed comparable performances (difference on RMSE 3-13 W/m $\mathrm{m}^{2}$ ) in the prediction of solar radiation incident into the community ground. The previously proposed formulas performed poorly in the prediction of surface convective heat transfer coefficient for the community hard pavement, and the power function regressed by using the measuring data performed well, with the air speed at the reference height of $0.13 \mathrm{~m}$ as variable and $\mathrm{R}^{2}$ of 0.74 . The Bowen ratio method performed better in the prediction of latent heat for the community permeable sidewalk, with RMSE of 156 $\mathrm{W} / \mathrm{m}^{2}$ and the consistency index of 0.93 . This study provides the field evidences and reliable methods for urban GEB calculation, and potentially contributes to the UHI prediction and mitigation in South China.
\end{abstract}

\begin{tabular}{|c|c|c|c|c|c|}
\hline \multicolumn{6}{|c|}{ Nomenclature } \\
\hline$R_{n}$ & net radiation & $\mathrm{W} / \mathrm{m}^{2}$ & $h$ & $\begin{array}{l}\text { surface convective heat transfer } \\
\text { coefficient }\end{array}$ & $\mathrm{W} /\left(\mathrm{m}^{2} \cdot \mathrm{K}\right)$ \\
\hline$T_{s}$ & surface temperature & $\mathrm{K}$ & $T_{a}$ & near surface air temperature & $\mathrm{K}$ \\
\hline LE & latent heat & $\mathrm{W} / \mathrm{m}^{2}$ & $\mathrm{G}$ & conductive heat flux & $\mathrm{W} / \mathrm{m}^{2}$ \\
\hline$S_{G}$ & net solar radiation on the ground & $\mathrm{W} / \mathrm{m}^{2}$ & $I_{D H}$ & $\begin{array}{l}\text { solar direct radiation on the } \\
\text { ground }\end{array}$ & $\mathrm{W} / \mathrm{m}^{2}$ \\
\hline$I_{S H}$ & solar diffuse radiation on the ground & $\mathrm{W} / \mathrm{m}^{2}$ & $S V F$ & sky view factor of ground & - \\
\hline$\alpha_{W}$ & reflection ratio of wall & & $F_{\mathrm{W}-\mathrm{G}}$ & $\begin{array}{l}\text { angle factor of wall to the } \\
\text { measured site }\end{array}$ & - \\
\hline$A$ & the area of the wall & $\mathrm{m}^{2}$ & $A_{S}$ & the area of shadow on the wall & - \\
\hline$h_{s}$ & solar elevation angle & $\circ$ & $\gamma$ & $\begin{array}{l}\text { the angle of solar azimuth and } \\
\text { normal direction of wall }\end{array}$ & $\circ$ \\
\hline$F_{\mathrm{W}-\mathrm{S}}$ & sky view factor of wall & - & $v$ & velocity & $\mathrm{m} / \mathrm{s}$ \\
\hline$\Delta$ & $\begin{array}{l}\text { slope of the water vapor saturation } \\
\text { pressure to the air temperature }\end{array}$ & - & $p_{q, b}^{a}$ & $\begin{array}{c}\text { water vapor saturation pressure } \\
\text { near the surface }\end{array}$ & $\mathrm{kPa}$ \\
\hline$p_{q}^{a}$ & water vapor pressure & $\mathrm{kPa}$ & $r_{a}$ & aerodynamic resistance & $\mathrm{s} / \mathrm{m}$ \\
\hline$r_{c}$ & surface resistance & - & $h^{\prime}$ & moisture transfer coefficient & $\mathrm{kg} /\left(\mathrm{m}^{2} \cdot \mathrm{s} \cdot \mathrm{Pa}\right)$ \\
\hline
\end{tabular}

\footnotetext{
* Corresponding author: zhangyuf@,scut.edu.cn
} 


\section{Introduction}

Urban heat island (UHI) greatly influences human health, comfort and building energy, and the problem becomes more and more serious with the global climate change and fast urbanization. The modification of land surfaces is one of the main causes of UHI. Compared to that of the natural and suburb lands, hard pavement covers over $80 \%$ of the grounds in cities, with larger heat capacity, higher solar radiation absorptivity and less latent heat dissipation, resulting in much higher ground temperature. The ground temperature plays an important role in understanding UHI, and the method based on the ground energy balance (GEB) is fundamental in the predictions of urban ground temperature and UHI.

South China is one of the fast developed and highly urbanized regions in China. It is in the humid subtropical climate zone, with a long, hot and humid summer, and a short and temperate winter. The UHI in summer causes many serious problems including heat stroke, hot discomfort, and huge cooling energy [1]. Although amounts of methods or formulas have been previously proposed for urban GEB calculation (see more details in the following corresponding sections), few of them has been testified in field in South China. The special humid subtropical climate and the particular urban design characteristics make the study in South China worth carrying out.

This study was aimed to determine the proper GEB calculation methods for the typical urban communities in South China through field study. The typical communities were selected through a large-sample survey in Guangzhou, a typical city in South China, the field measurements on the key components of GEB were conducted in the communities during summer sunny days, and the previously proposed GEB calculation methods were evaluated by comparing with the measured data. This study provides the field evidences and reliable methods for urban GEB calculation, and potentially contributes to the UHI prediction and mitigation in South China.

\section{Methodology}

A survey on 107 communities was conducted in Guangzhou, with the focus on their design characteristics of layout, building height, façade, and orientation. The statistical analysis showed that the dominant community layouts were the aligned and enclosed types. The typical designs for the aligned layout communities are high-rise, north-south orientated, with light-colored façades and the depth-width ratio between 0.88 and 1.82 . The typical designs for the enclosed layout communities are high-rise, all enclosed and with light-colored façades. And accordingly, aligned layout Community A, 11 storeys high, north-south orientated, with grey façades and aspect ratio of 1 , and enclosed layout Community B, 15 storeys high and with grey façades, were chosen as the study sites (Fig. 1).

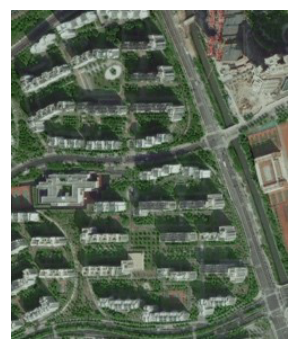

(a) Community A

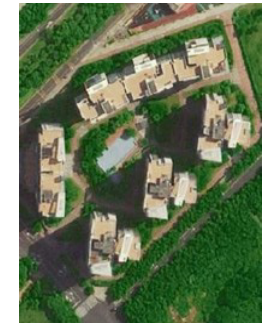

(b) Community B
Fig.1. Study sites

The GEB can be generally expressed as:

$$
R_{n}=\mathrm{h}\left(T_{s}-T_{a}\right)+\mathrm{LE}+\mathrm{G}
$$

Solar radiation, sensible and latent heats are the important items in GEB. The solar radiation incident into the ground changes greatly with the community layout, and Community A and B were therefore both measured. The measuring points were located at the public activity spaces in the communities that are away from trees and sunshade structures, and the incident solar radiations were measured near the grounds by a net pyrradiometer (Fig. 2a). The boundary solar radiations were measured simultaneously at the open spaces close to the study sites (Fig. 2b). The sky view factor (SVF) to be used in the calculations were measured as well at the measuring points. The detailed information on the instruments is shown in Table 1. The measurements were conducted during summer sunny days, i.e., Aug. 6, 2017 for Community A, and Aug. 7-8, 2017 for Community B.

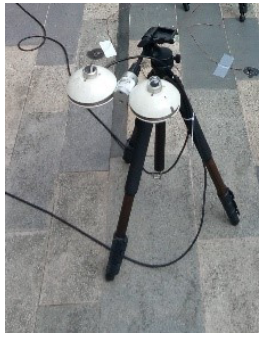

(a) Community

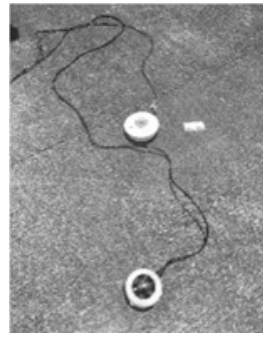

(b) Boundary
Fig.2. Solar radiation measurement

The sensible heat can be obtained by subtracting the conductive heat from the net radiation under the weather conditions of sunny days when the latent heat can be neglected, and accordingly, the surface convective heat transfer coefficient (SCHTC) can be derived by:

$$
\mathrm{h}=\frac{R_{n}-G}{T_{s}-T_{a}}
$$

The sensible heat measurement was conducted on the hard pavement in Community A on Aug. 6, 2017. The net radiation, conductive heat, surface and air temperatures were measured continuously, and the near-ground air velocities were recorded at three heights as well, referring to Fig. 3a and Table 1 for the details. 
The latent heat was obtained as the residue of GEB:

$$
\mathrm{LE}=R_{n}-G-h\left(T_{s}-T_{a}\right)
$$

The latent heat measurement was conducted on the permeable sidewalk in Community B on Aug. 8, 2017. Water was sprayed on the sidewalk to keep the surface wet during the measurement. Besides the items in the sensible heat measurement, the air humidity was measured at 1.5 $\mathrm{m}$ height above the ground in the latent heat measurement (see Fig. 3 b and Table 1).

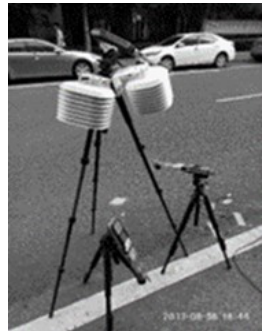

(a) Sensible heat

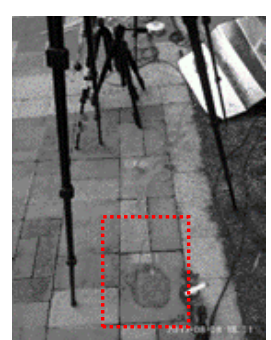

(b) Latent heat
Fig.3. Sensible and latent heat measurements

Table 1 Measuring items, instruments and methods

\begin{tabular}{|c|c|c|c|}
\hline Items & Instruments & Accuracy & Methods \\
\hline $\begin{array}{l}\text { Boundary solar } \\
\text { radiation }\end{array}$ & Pyrradiometer（SPN1） & $\pm 5 \%$ from 400 to $2700 \mathrm{~nm}$ & At open spaces \\
\hline Net radiation & Net pyrradiometer (NR-01) & $\pm 10 \%$ from 305 to $2800 \mathrm{~nm}$ & $\begin{array}{c}\text { At a height of } 0.5 \mathrm{~m} \text { parallel to the } \\
\text { ground }\end{array}$ \\
\hline SVF & HemiView & & At a height of $1.5 \mathrm{~m}$ \\
\hline $\begin{array}{l}\text { Air temperature and } \\
\text { humidity }\end{array}$ & $\begin{array}{l}\text { Temperature and humility recorder } \\
\text { (HOBO U23-001) }\end{array}$ & $\begin{array}{l} \pm 0.2{ }^{\circ} \mathrm{C} \text { from } 0 \text { to } 50{ }^{\circ} \mathrm{C} \\
\pm 2.5 \% \text { from } 10 \% \text { to } 90 \%\end{array}$ & At a height of $1.5 \mathrm{~m}$ \\
\hline Air velocity & Thermal index instrument (HD32.3) & $\begin{array}{l} \pm 0.05 \mathrm{~m} / \mathrm{s} \text { from } 0 \text { to } 1 \mathrm{~m} / \mathrm{s} \\
\pm 0.15 \mathrm{~m} / \mathrm{s} \text { from } 1 \text { to } 5 \mathrm{~m} / \mathrm{s}\end{array}$ & $\begin{array}{c}\text { At heights of } 0.13 \mathrm{~m}, 0.6 \mathrm{~m} \text { and } 1.5 \\
\mathrm{~m} \text {, separately }\end{array}$ \\
\hline Conductive heat flux & $\begin{array}{c}\text { Heat flow meter } \\
(\text { HS-10) }\end{array}$ & $>3 \%$ from -200 to $200 \mathrm{~kW} / \mathrm{m}^{2}$ & $\begin{array}{l}\text { For sensible heat flux measurement, } \\
\text { covered by thin ground powder }\end{array}$ \\
\hline Surface temperature & $\begin{array}{l}\text { Thermocouple(T) and recorder } \\
\text { (UX120-014M) }\end{array}$ & $\pm 0.21{ }^{\circ} \mathrm{C}$ from 0 to $50{ }^{\circ} \mathrm{C}$ & \\
\hline Conductive heat flux & $\begin{array}{l}\text { Heat flow meter } \\
\text { (HS-100P) }\end{array}$ & $>3 \%$ from -200 to $200 \mathrm{~kW} / \mathrm{m}^{2}$ & $\begin{array}{l}\text { For latent heat flux measurement, } \\
\text { covered by thin ground powder }\end{array}$ \\
\hline
\end{tabular}

\section{Results and discussion}

\subsection{Solar radiation}

\subsubsection{The measured values}

The time changes of boundary solar radiations measured at the open spaces are given in Fig. 4. Similar trend was presented in three days: stronger at noon and weaker in the morning and afternoon. The fluctuation was slightly larger on Aug. 6, and long-time low values occurred in the afternoon on Aug. 8, both of which were mainly attributed to the movements of clouds. The observed time changes in solar radiations are typical in the summer sunny days in South China.

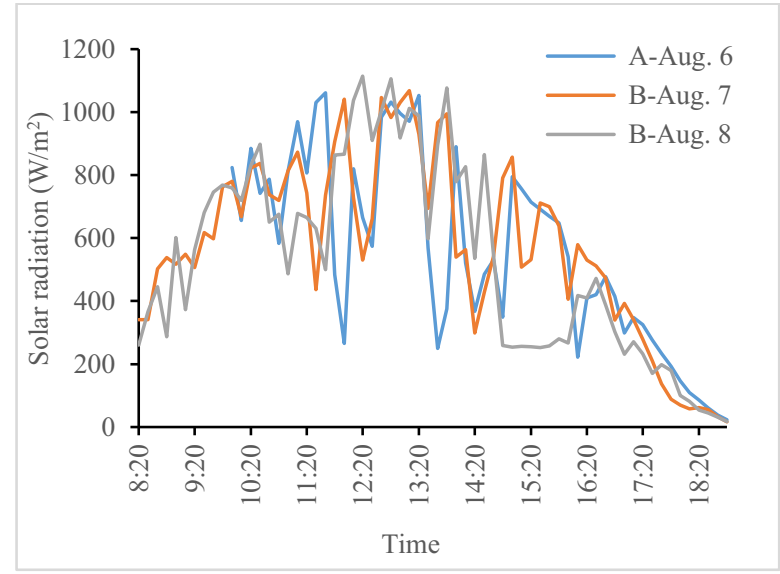

Fig.4. Time changes of boundary solar radiations

The time change of solar radiation incident into the ground of Community A is displayed in Fig. 5, together with the boundary one. The changing trends were quite similar for the community and boundary values. The community solar radiation was weaker than the boundary one for most of the time due to the sunshade of surrounding buildings. There is one exception between 14:00 and 14:20, when the values for the community ground were higher, mainly caused by the phase deviation between the community and boundary values (distant by $1 \mathrm{~km}$ for the two points). 


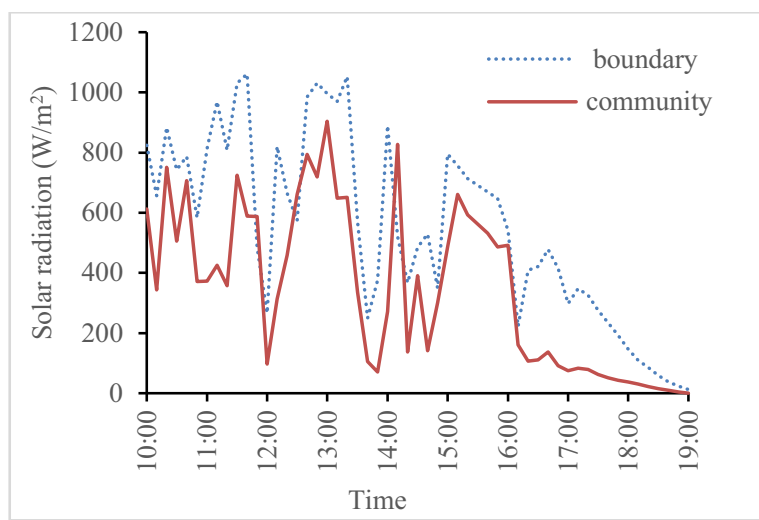

Fig.5. Time change of solar radiation on the ground in Community A

The time change of solar radiation incident into the ground of Community B is presented in Fig. 6 and 7, for the two days respectively. The most notable finding is that the solar radiation in Community B kept at a low level in the whole morning while the boundary one ascended to high values, indicating a severe block of direct sunlight by the buildings. After the noon, the community values increased rapidly and maintained a similar changing trend with that of the boundary one.

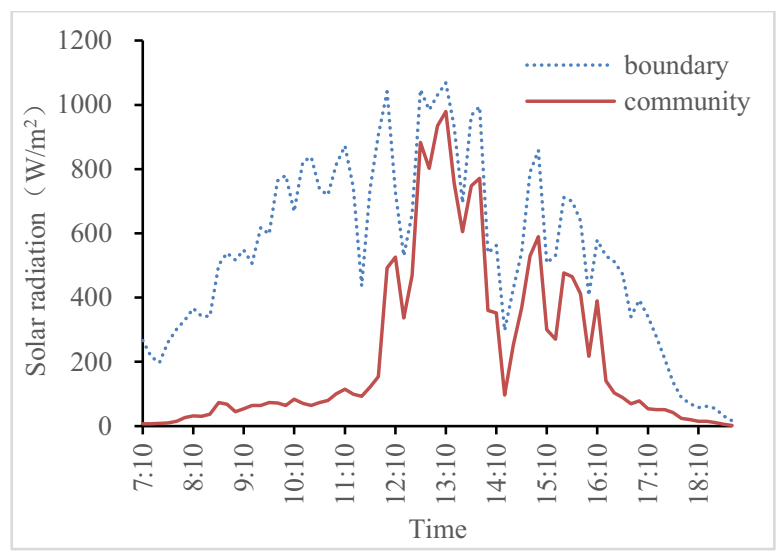

Fig.6. Time change of solar radiation on the ground in Community B (Aug. 7)

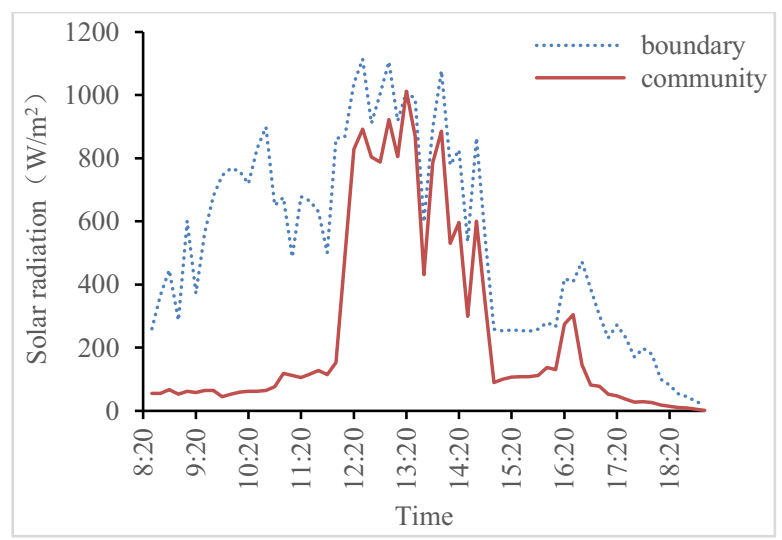

Fig.7. Time change of solar radiation on the ground in Community B (Aug. 8)

\subsubsection{Evaluations of calculation methods}

Two calculation methods for ground solar radiation, i.e., with and without reflections, were evaluated in this study. For the case without reflections, the solar radiation was calculated as [2-3]:

$$
S_{G}=I_{D H}+I_{S H} S V F
$$

for the condition in the shadow, and as:

$$
S_{G}=I_{S H} S V F
$$

for the condition in the sunshine. For the case with reflections, primary reflections were included in the solar radiation calculation by:

$$
\begin{aligned}
& S_{G} \\
& =I_{S H} S V F\left(\mathrm{OR} I_{D H}+I_{S H} S V F\right) \\
& +\alpha_{W} \sum_{i=1}^{n} F_{\mathrm{W}-G}\left(\frac{A-A_{S}}{A} \frac{I_{D H}}{\tan h_{S}} \cos \gamma\right. \\
& \left.+I_{S H} F_{W-S}\right)
\end{aligned}
$$

The comparison between the calculated and measured solar radiations for community $\mathrm{A}$ is shown in Fig. 8. The calculated and measured values followed the same time trend, the calculated values were higher than the measured ones for most of the time, and the values by the two calculation methods were very close. It can be further observed that the calculated and measured values were close to each other when the boundary and community solar radiations changed synchronously, and apart when the changes were asynchronous, indicating the error mainly attributing to that of the boundary condition. The root mean square error (RMSE) values were determined to be $166 \mathrm{~W} / \mathrm{m}^{2}$ and $162 \mathrm{~W} / \mathrm{m}^{2}$ for the cases with and without reflections, respectively. The errors were quite large, mainly attributed to the boundary conditions as aforementioned. The consistency index (CI) was 0.91 and close to 1 for the two calculation cases.

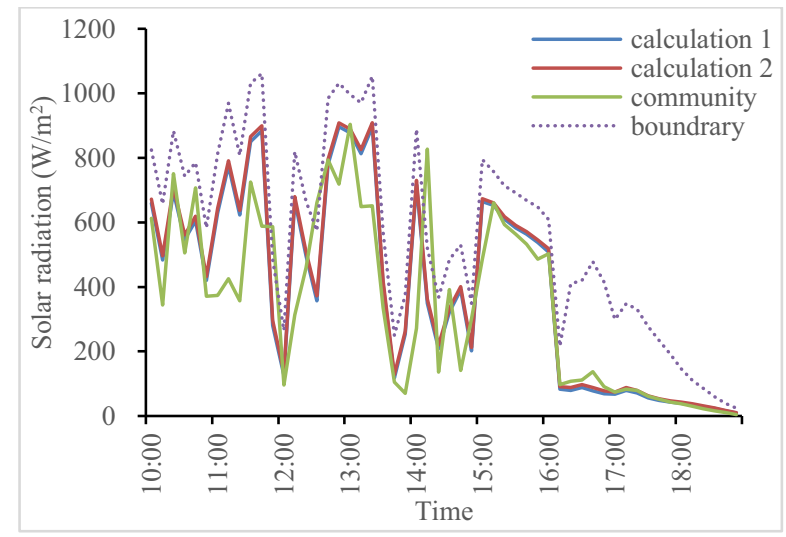

${ }^{1}$ Without reflections

${ }^{2}$ With reflections

Fig.8. Comparison of calculated and measured solar radiations for Community $\mathrm{A}$ 
The comparisons between the calculated and measured solar radiations for community B are shown in Fig. 9 and 10. The time trends of the calculated and measured values kept the same. The calculated values with reflections were slightly higher than those without in most cases. Both of the calculated values coincided with the measured results at some time of the day, i.e., at noon for those with reflections, and in the morning and afternoon for those without, indicating that the impact of solar reflections varied with the intensity of incident solar radiation.

The RMSE values were $68 \mathrm{~W} / \mathrm{m}^{2}$ and $55 \mathrm{~W} / \mathrm{m}^{2}$ for the cases with and without reflections for the data on Aug. 7 , and $66 \mathrm{~W} / \mathrm{m}^{2}$ and $63 \mathrm{~W} / \mathrm{m}^{2}$ for Aug. 8. The CI values were all close to 1 . The errors in Community B were much less than those in Community A.

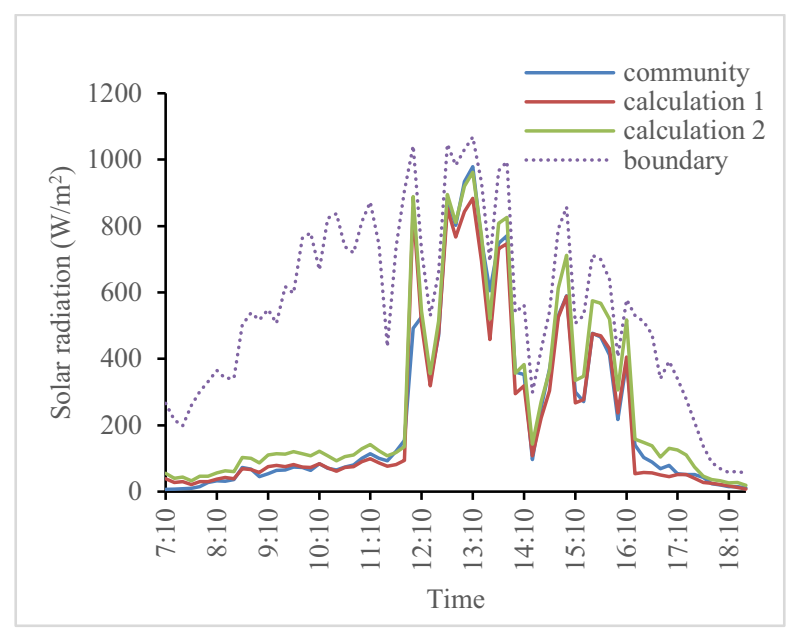

Fig.9. Comparison of calculated and measured solar radiations for Community B (Aug. 7)

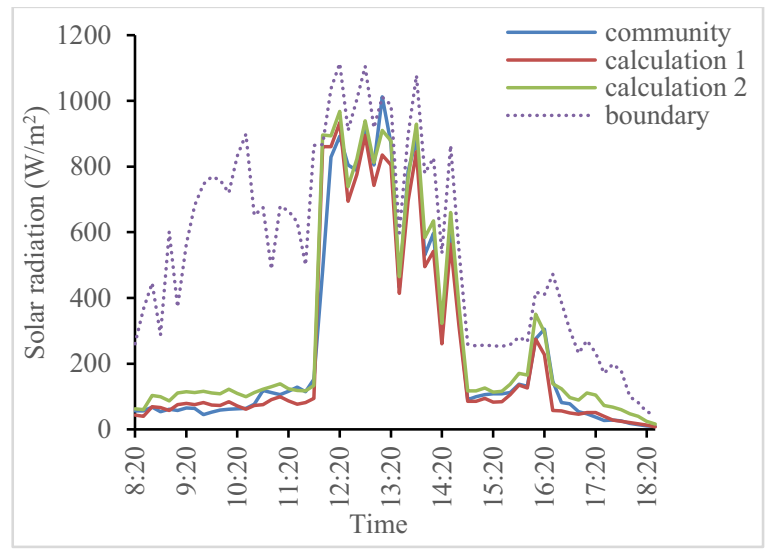

Fig.10. Comparison of calculated and measured solar radiations for Community B (Aug. 8)

\subsection{Sensible heat}

\subsubsection{The measured values}

The time changes of net radiation, conductive heat, and surface and air temperatures for the hard pavement are shown in Fig.11. The net radiation fluctuated greatly with the incident solar radiation (Fig. 5), causing corresponding changes of conductive heat and surface temperature, whereas the air temperature varied more slightly and slowly.

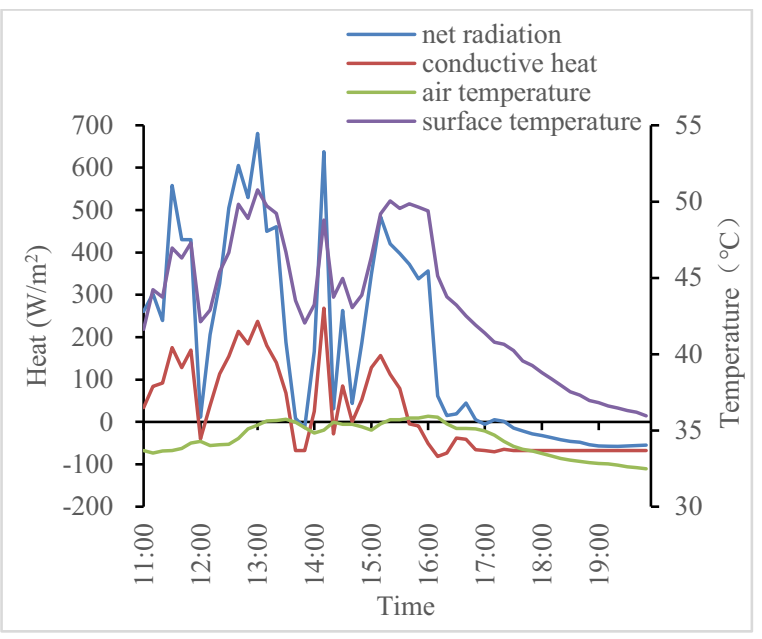

Fig.11. Time changes of sensible heat measured values

The time change of SCHTC at the measuring point is given in Fig. 12. It mainly followed the trend of net radiation. The SCHTC was large and dramatically fluctuated during the daytime, and became small and stable in the evening. The fluctuation may be induced by the large velocity changes and temperature difference between the surface and the air.

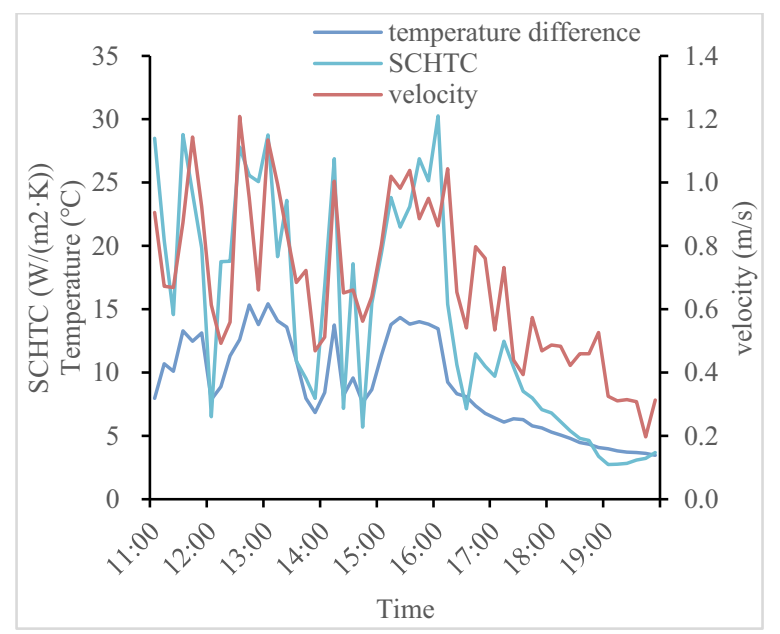

Fig.12. Time change of SCHTC

\subsubsection{Evaluations of calculation methods}

The surface sensible heat is usually obtained by multiplying the surface and near-surface air temperature difference with SCHTC, and the SCHTC is critical to the sensible heat calculation. The SCHTC is generally predicted by the formulas with air velocity, such as: 


$$
\text { Jurges [4]: } \mathrm{h}=\left\{\begin{array}{c}
6.15+4.18 v \quad v \leq 5 \mathrm{~m} / \mathrm{s} \\
7.51 v^{0.78} \quad v>5 \mathrm{~m} / \mathrm{s}
\end{array}\right.
$$

or:

$$
\text { Hagishima [5]: } h=3.96 v+6.42
$$

, or together with the surface and near-surface air temperature difference as:

$$
\text { Kehlbeck [6]: } \mathrm{h}=2.6[\sqrt[4]{\Delta t}+1.54 v]
$$

The reference height for air velocity is inconsistent or not clearly defined in the previously proposed formulas. It has been found that the SCHTC formulas may change greatly at different reference heights [8]. Therefore, three typically occurred reference heights $(0.13 \mathrm{~m}, 0.6 \mathrm{~m}$, and $1.5 \mathrm{~m}$ ) were studied in this paper.

The calculated and measured SCHTCs are compared in Fig.13 at three reference heights. For the reference height of $0.13 \mathrm{~m}$ (Fig. 13a), all formulas performed well for the velocity range of $0.4-0.6 \mathrm{~m} / \mathrm{s}$. When velocity was lower, the Kehlbeck formula was more accurate, followed by the Hagishima one. When velocity was higher, all calculated values were less than the measured one, and the gap became larger as the velocity increased. The smallest RMSE was $9.58 \mathrm{~W} /\left(\mathrm{m}^{2} \cdot \mathrm{K}\right)$ for the Jurges formula, and the largest CI was 0.56 for the Hagishima formula (see Table 2).

The results are slightly different for the reference height of $0.6 \mathrm{~m}$ (Fig. 13b). The calculated values were close to the measured one when the velocity was $<0.4 \mathrm{~m} / \mathrm{s}$, and less when $>0.4 \mathrm{~m} / \mathrm{s}$. The RMSE values were all larger than those at the reference height of $0.13 \mathrm{~m}$, and the largest CI was 0.53 for the Kehlbeck formula (Table 2). Similar results were found at the reference height of $1.5 \mathrm{~m}$ (Fig. $13 \mathrm{~b}$ ), with the smallest RMSE of $9.22 \mathrm{~W} /\left(\mathrm{m}^{2} \cdot \mathrm{K}\right)$ for the Jurges formula and the largest $\mathrm{CI}$ of 0.58 for the Kehlbeck formula (Table 2).

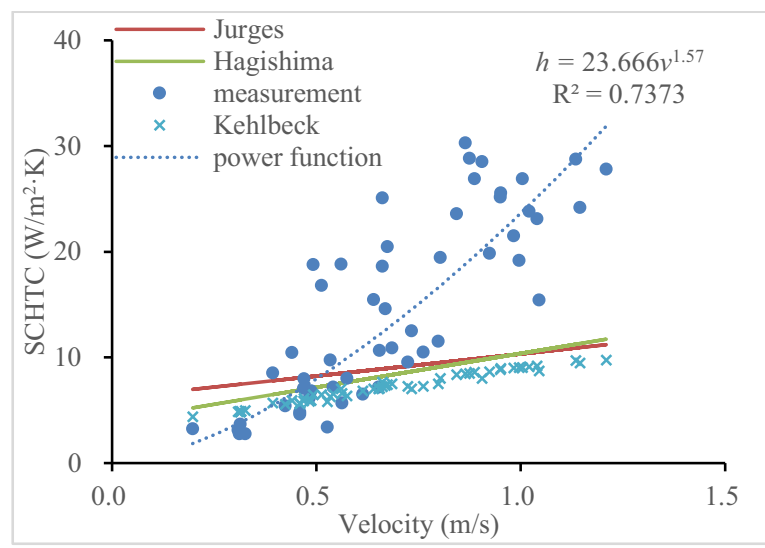

(a) At reference height of $0.13 \mathrm{~m}$

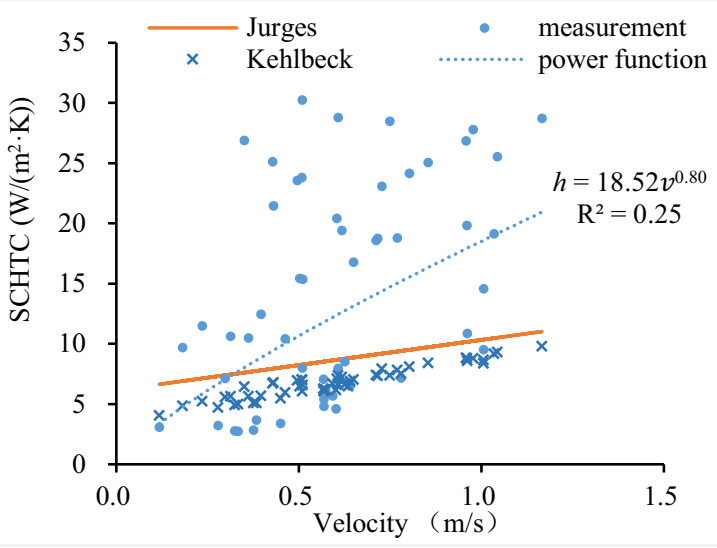

(b) At reference height of $0.6 \mathrm{~m}$

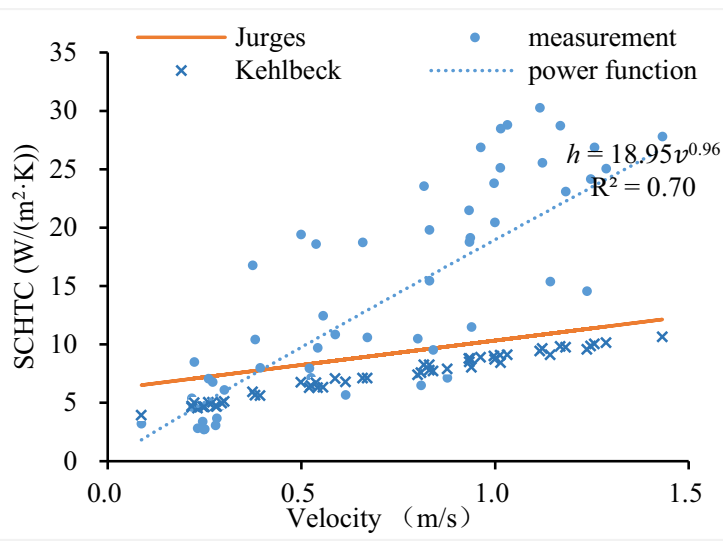

(c) At reference height of $1.5 \mathrm{~m}$

Fig.13. Comparison of calculated and measured SCHTCs

Table 2 Performances of the SCHTC formulas

\begin{tabular}{ccccc}
\hline $\begin{array}{c}\text { Reference } \\
\text { height }(\mathrm{m})\end{array}$ & Evaluation index & Jurges & Kehlbeck & Hagishima \\
\hline \multirow{2}{*}{0.13} & $\mathrm{RMSE}\left(\mathrm{W} /\left(\mathrm{m}^{2} \cdot \mathrm{K}\right)\right)$ & $\mathbf{9 . 5 8}$ & 10.45 & 9.64 \\
& $\mathrm{CI}$ & 0.52 & 0.55 & $\mathbf{0 . 5 6}$ \\
0.60 & $\mathrm{RMSE}\left(\mathrm{W} /\left(\mathrm{m}^{2} \cdot \mathrm{K}\right)\right)$ & $\mathbf{1 0 . 1 1}$ & 10.96 & \\
& $\mathrm{CI}$ & 0.49 & $\mathbf{0 . 5 3}$ & \\
1.50 & $\mathrm{RMSE}\left(\mathrm{W} /\left(\mathrm{m}^{2} \cdot \mathrm{K}\right)\right)$ & $\mathbf{9 . 2 2}$ & 10.14 & \\
& $\mathrm{CI}$ & 0.55 & $\mathbf{0 . 5 8}$ & \\
\hline
\end{tabular}

The SCHTC in theory changes with the geometric factors of the surface including surface size, roughness, shape, and the relative position to the fluid. The surfaces of buildings are the focus of the majority of previous SCHTC studies, and this might be the reason for the large calculation errors for the pavement in community. The relationship between SCHTC and the near-ground air velocity was hence regressed by directly using the measured data. It was found that the power function performed the best with the air speed at the reference height of $0.13 \mathrm{~m}$ as variable and $\mathrm{R}^{2}$ of 0.74 (see Fig.13):

$$
h=23.67 v^{1.57}
$$




\subsection{Latent heat}

\subsubsection{The measured values}

The time changes of net radiation, conductive, sensible and latent heats of the permeable sidewalk are shown in Fig.14. The net radiation followed the incident solar radiation in Fig. 7. The conductive and sensible heats showed obvious delay when compared to that of radiation, with the maximum occurring at 15:00. The latent heat followed the radiation closely, with the maximum at 13:00. Negative latent heats occasionally appeared in the afternoon, mainly caused by the extra heat absorption of the water that sprayed at that time. The negative data was excluded in the subsequent analysis.

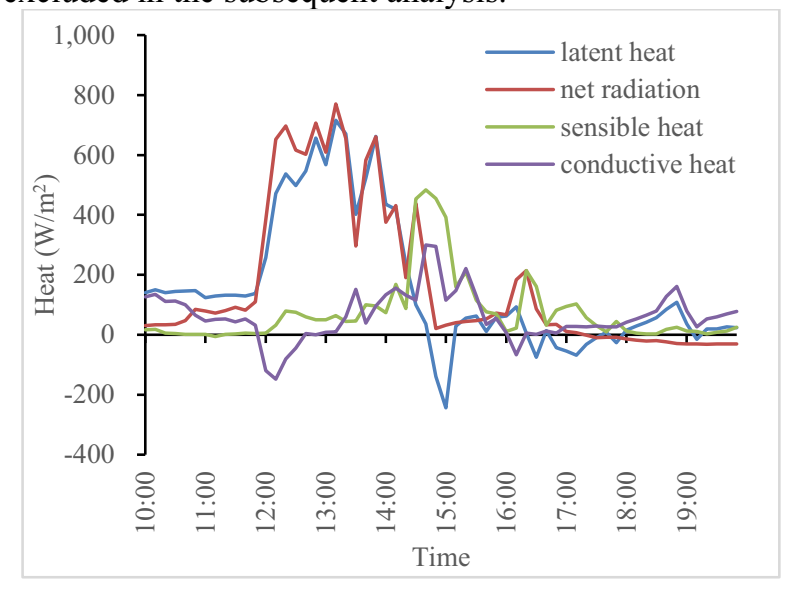

Fig.14. Time changes of latent heat measured values

\subsubsection{Evaluation of calculation methods}

Three well-known methods to calculate latent heat, i.e., the Penman-Monteith (Eq. (11)), Bowen ratio (Eq. (12)), and water vapor pressure (or humidity) difference (Eq. (13)) [7] methods were evaluated in this study.

$$
\begin{gathered}
L E=\frac{\Delta\left(R_{n}-G\right)+\rho c_{p}\left(p_{q, b}^{a}-p_{q}^{a}\right) / r_{a}}{\Delta+\gamma\left(1+r_{c} / r_{a}\right)} \\
L E=\frac{R_{n}-G}{1+\gamma \frac{d T}{d p}} \\
L E=L^{\prime} \beta_{i}\left(p_{q, b}^{s}-p_{q}^{a}\right)
\end{gathered}
$$

The measured and calculated latent heats are presented in Fig. 15. The $\mathrm{R}^{2}$ of the Bowen ratio method was highest, while the one of the water vapor pressure difference method was lowest. It may relate to the water spray. The conductive heat changed immediately once the water was sprayed on the surface. The Penman-Monteith and Bowen ratio methods considered this well by including conductive heat in formulas, whereas the water vapor pressure difference method cannot capture such quick changes. The Penman-Monteith method is generally used in agriculture or large lakes, while the Bowen ratio method is applied more widely. Compared with those of the other two methods, the Bowen ratio method showed the best, with RMSE of $156 \mathrm{~W} / \mathrm{m}^{2}$ and CI of 0.93 (see Table 3).

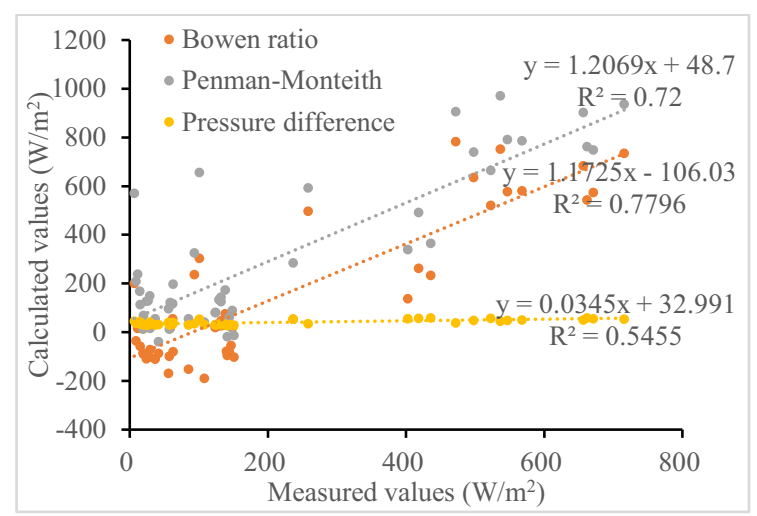

Fig.15. The measured and calculated latent heats

Table 3 Performances of the latent heat calculation methods

\begin{tabular}{lll}
\hline Calculation method & Evaluation index & \\
\hline Penman-Monteith & $\mathrm{RMSE}\left(\mathrm{W} /\left(\mathrm{m}^{2} \cdot \mathrm{K}\right)\right)$ & 192 \\
& $\mathrm{CI}$ & 0.93 \\
Bowen ratio & $\mathrm{RMSE}\left(\mathrm{W} /\left(\mathrm{m}^{2} \cdot \mathrm{K}\right)\right)$ & $\mathbf{1 5 6}$ \\
& $\mathrm{CI}$ & $\mathbf{0 . 9 3}$ \\
Water vapor & $\mathrm{RMSE}\left(\mathrm{W} /\left(\mathrm{m}^{2} \cdot \mathrm{K}\right)\right)$ & 297 \\
pressure difference & $\mathrm{CI}$ & 0.21 \\
& & \\
\hline
\end{tabular}

\section{Conclusions}

In this study, two typical urban communities in South China in the aligned and enclosed layout were measured during the summer sunny days in Aug. 2017, with the focus on incident solar radiation, sensible heat, and latent heat of the ground. The measured data were compared with the calculated ones by various methods. The main conclusions are as follows:

(1) The two calculation methods, i.e., with and without reflections, showed comparable performances (difference on RMSE 3-13 W/m $/ \mathrm{m}^{2}$ ) in the prediction of solar radiation incident into the community ground.

(2) The previously proposed formulas performed poorly in the prediction of SCHTC for the hard pavement in the community, with RMSE larger than $9.22 \mathrm{~W} /\left(\mathrm{m}^{2} \cdot \mathrm{K}\right)$ and $\mathrm{CI}$ lower than 0.58 . The power function regressed by using the measuring data performed well, with the air speed at the reference height of $0.13 \mathrm{~m}$ as variable and $\mathrm{R}^{2}$ of 0.74 .

(3) The Bowen ratio method performed better in the prediction of latent heat for the permeable sidewalk in the community than the Penman-Monteith and vapor pressure difference methods, with RMSE of $156 \mathrm{~W} / \mathrm{m}^{2}$ and CI of 0.93 .

The GEB calculation method that combining the incident solar radiation without reflections, the regressed power function for SCHTC, and the Bowen ratio method is thus proposed as the reliable method for the urban GEB calculation in South China. Furthermore, it is advised to choose the open space as close to the measured site as 
possible for the solar radiation boundary, and to study the latent heat for the unsaturated surface and under the natural rainfall conditions as well.

This research was financed by National Natural Science Foundation of China (E080301) and Guangxi Science and Technology Project (AB18050012).

\section{References}

1. K. Pantavou, G. Theoharatos, A. Mavrakis, M. Santamouris, BUILD ENVIRON. 2, 46, (2011)

2. H. Kusaka, H. Kondo, Y. Kikegawa, F. Kimura, BdyL Met. 3, 101, (2001)

3. H. Kondo, Y. Genchi, Y. Kikegawa, Y. Ohashi, H. Yoshikado, H. Komiyama, Bdy-L Met. 3, 116, (2005)

4. H. Kusaka, H. Kondo, Y. Kikegawa, F. Kimura, BdyL Met. 101, 3(2001)

5. A. Hagishima, J. Tanimoto, BUILD ENVIRON. 7(2003)

6. F Kehibeck. Effect of solar radiation on bridge structure. Xf, Liu, Translated. Beijing: Chinese Railway Publisher (1981)

7. M. Shuzo. CFD and Built Environment Design. Qy, Zhou, Translated. Beijing: Chinese Construction Industry Press (2007) 